\title{
Primer taller de orfebrería prehispánica excavado en Colombia (siglos IX-XVI d. C.)
}

\author{
The First Prehispanic Goldsmith Workshop \\ Excavated in Colombia ( $9^{\text {th }}-16^{\text {th }}$ centuries AD)
}

\author{
Juan Manuel Llanos Chaparro \\ Departamento de Estudios Interdisciplinarios, Instituto de Educación a Distancia, \\ Universidad del Tolima, Colombia \\ jmllanos@gmail.com
}

\begin{abstract}
RESUMEN
En el presente artículo se exponen de manera sucinta los resultados más relevantes de la primera excavación arqueológica en Colombia realizada en un taller orfebre prehispánico que funcionó por más de ochocientos años en la cuenca baja del río Saldaña, valle del Magdalena. Los grupos humanos establecidos en el lugar durante el periodo Tardío (siglos IX-XVII d. C.) contaban con los conocimientos técnicos (martillado-recocido y vaciado a la cera perdida), las herramientas (cerámica refractaria e industria lítica) y los recursos forestales y minerales necesarios para elaborar piezas en cobre y oro de alta calidad, complejidad y tamaño (pectorales acorazonados, figuras antropomorfas y zoomorfas con extremidades en escuadra). La tecnología empleada, aunque en apariencia "sencilla" por la ausencia de hornos o estructuras pirotecnológicas complejas, era muy eficiente.
\end{abstract}

Palabras clave: arqueometalurgia, periodo Tardío, taller orfebre, cerámica refractaria y cera perdida.

\begin{abstract}
In this paper the main results of the first archaeological dig in Colombia of a pre-Hispanic goldsmith workshop are presented succinctly; this workshop worked over 800 years in the lower basin of the Saldaña river (Magdalena Valley). Human groups settled there during the late period $\left(9^{\text {th }}-17^{\text {th }} \mathrm{C}\right.$. AD) had technical expertise (hammered-annealing, lost wax casting and emptying), tools (refractory ceramic and lithic industry) and forest resources and minerals needed to produce parts in copper and gold high quality, complexity and size (heartlike pectorals, anthropomorphic and zoomorphic figures with tips on bracket). The technology used, although it seems "simple", by the absence of pyro-technological ovens or complex structures, was very efficient.
\end{abstract}

Keywords: archaeometallurgy, Late period, goldsmith workshop, refractory ceramic and lost wax casting. 


\section{Introducción}

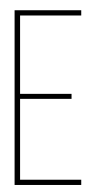

n el contexto colombiano, los objetos de metal prehispánicos han jugado un papel importante por su calidad técnica, su riqueza expresiva y su relativa abundancia. Desafortunadamente, la investigación no se ha desarrollado de manera sistemática y continua; el interés se concentró en los análisis formales y su asociación cultural, pero son escasos los trabajos orientados a conocer el desarrollo de la tecnología metalúrgica y su vinculación con el contexto sociohistórico (Lleras 2007b). José Pérez de Barradas, en su obra pionera Orfebrería prehispánica de Colombia (1958), acuña la expresión estilo orfebre Tolima, lo define y reconoce la cuenca del Saldaña como un lugar altamente especializado, “un epicentro” para la obtención de materias primas, la elaboración y concentración de material orfebre. Es posible suponer que desde esta región se realizó la difusión de piezas a través de complejas redes de intercambio (Pérez de Barradas 1958).

Con el propósito de aportar información de utilidad para definir las pautas de asentamiento, la tipología cerámica, la cronología cultural y el contexto sociohistórico de la orfebrería del estilo Tolima, en el año 2000 se inició el Programa de Investigación de la Cuenca del Río Saldaña, en compañía de la antropóloga Sandra Gutiérrez Abella, el cual contó con el apoyo económico de la Fundación de Investigaciones Arqueológicas Nacionales (FIAN) del Banco de la Republica y el Fondo Mixto de Cultura del Departamento del Tolima. En la primera etapa de prospección en la cuenca baja (municipio de Saldaña) se ubicaron diez yacimientos arqueológicos (figura 1), de los cuales se escogieron dos para excavar (Saldaña 9 y 10). En el sitio Saldaña 10 se registraron abundantes fragmentos de cerámica refractaria, instrumentos líticos, dos anzuelos y una lámina elaborados en cobre, desechos de metal, escorias y materias primas (carbonatos de cobre); todos ellos conforman un conjunto de evidencias asociadas a un taller o área de actividad metalúrgica relacionada con la ocupación tardía (complejo cerámico Magdalena Inciso), fechada entre el siglo VIII d. C. y el XVI d. C. (Llanos 2001; Llanos y Gutiérrez 2006).

Las evidencias arqueológicas asociadas con el trabajo orfebre en Colombia corresponden a hallazgos aislados (Duque 1964-1966; Patiño 1997; Sáenz et al. 2007; Salgado et al. 2006, 2008). Como era la primera vez que en el país se excavaba de manera científica en este tipo de contextos, se decidió ampliar el área inicialmente intervenida y realizar una serie de análisis especializados de los materiales recuperados, como parte de la investigación destinada a obtener el título de doctor en Arqueología de la Universidad del Centro de la Provincia 


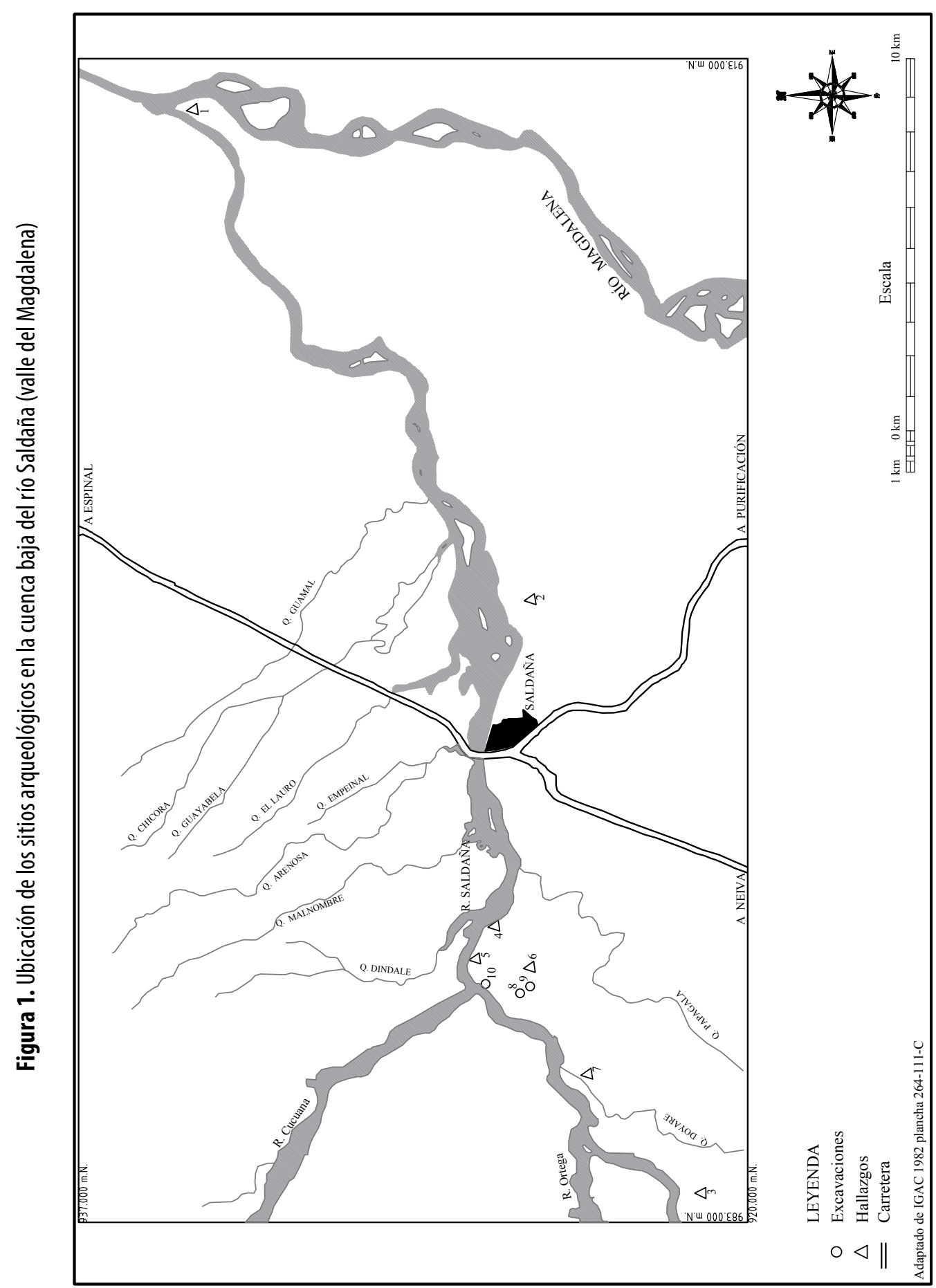


de Buenos Aires (Olavarría-Argentina), cuyos resultados más relevantes hacen parte integral de este artículo.

La investigación se desarrolló bajo los parámetros teórico-metodológicos propios de la arqueometalurgia, integrando elementos de las dos escuelas más reconocidas: cadena operatoria (Fraresso 2008; Lemonnier 1986, 1992) y estilo tecnológico (Lechtman 1977; Thornton 2012). El fin de esto era aportar un marco científico para el análisis y la evaluación de las variables técnicas, físicas y químicas presentes en las evidencias materiales, así como de las condiciones socioculturales bajo las cuales se fabricaron y emplearon los bienes de metal. Las evidencias obtenidas fueron contrastadas con los resultados de investigaciones similares adelantadas en Suramérica, entre las cuales se destacan las llevadas a cabo en el norte del Perú (Rengifo y Rojas 2008; Shimada, Goldstein y Wagner 2007), el noroeste argentino (Angiorama y Taboada 2007; González 2010) y el norte de Chile (Graffam, Carevic y Rivera 1997).

\section{Una ubicación estratégica}

El sitio arqueológico Saldaña 10 se encuentra ubicado sobre una terraza alta erosional-coluvial que se prolonga de forma paralela al curso del río Saldaña y es parte de un megaabanico de origen fluviovolcánico, modelado por el protorrío Saldaña (volcanes nevado del Huila y cerro Machín). Los suelos son ricos en nutrientes, pero tienen limitaciones de tipo natural, como la poca profundidad, la compactación, la presencia de materiales gruesos cerca de la superficie y la alta acidez, condiciones que, acompañadas del déficit hídrico, restringen la conformación de grandes asentamientos humanos por largos periodos. Los ocupantes prehispánicos aprovecharon esta posición para acceder al agua de manera permanente, así como las áreas bajas, cubiertas periódicamente por sedimentos aluviales, para el establecimiento de cultivos, y construyeron sus viviendas sobre las tierras altas, cementadas y bien drenadas. De esa manera, constituyeron dicha posición en un lugar estratégico que les permitió controlar un extenso territorio (figura 2).

En la actualidad, la región se encuentra en un periodo de erosión acelerada. La tala intensiva de los escasos parches de bosque seco tropical, que crecen a la orilla de los cursos de agua, las altas temperaturas y las lluvias características del clima cálido seco han significado la desaparición de la cobertura natural, con lo cual ha quedado expuesto el material parental en las colinas y terrazas circundantes al sitio (figura 2). 
Figura 2. Panorámica del sitio arqueológico Saldaña 10

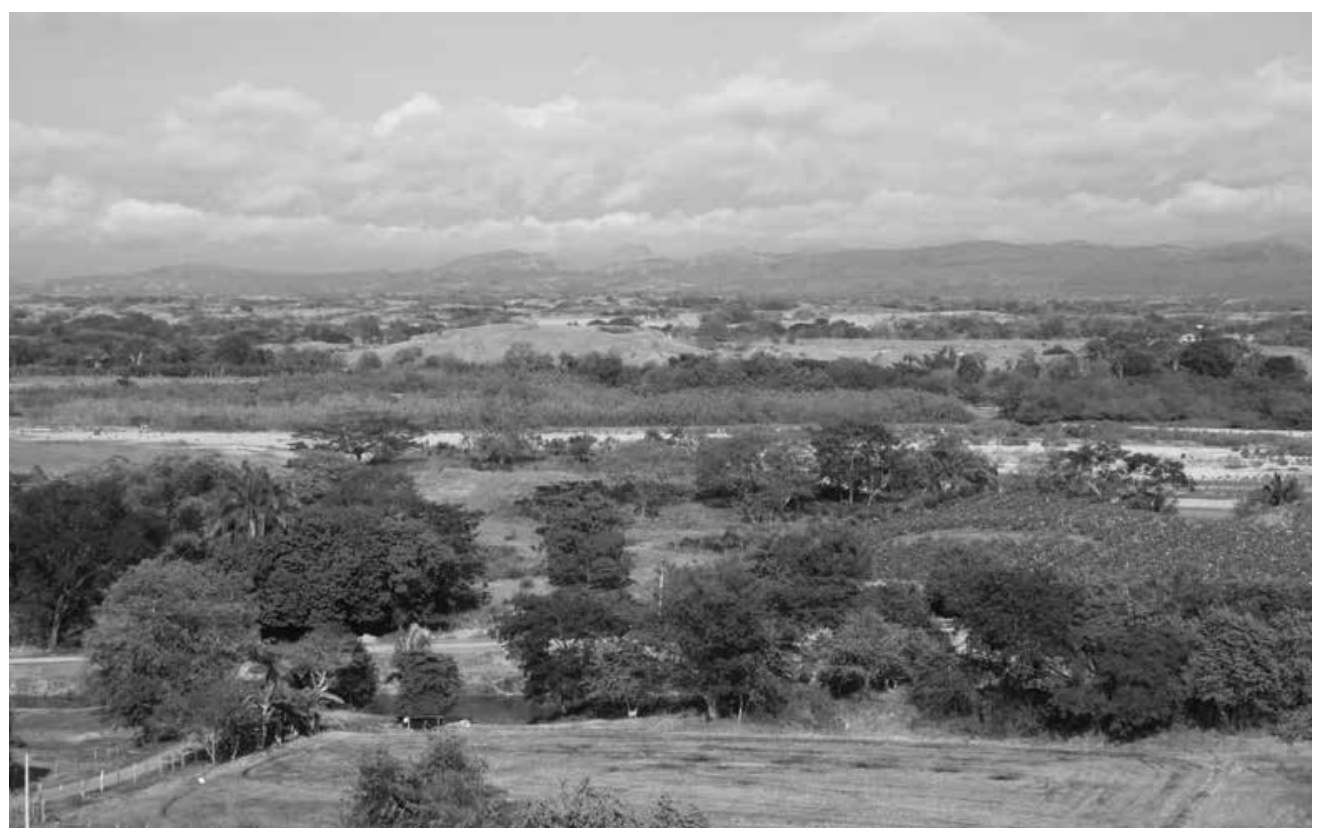

Fuente: Fotografía de Juan Manuel Llanos.

\section{Excavaciones arqueológicas}

Las evidencias arqueológicas se encuentran dispersas en una superficie aproximada de 8 hectáreas. En esta área se realizó una recolección sistemática de materiales diagnósticos, acompañada de líneas de pozos de sondeo que permitieron delimitar dos zonas; en la parte baja de la terraza (2,5 ha) se ubicaron las unidades de excavación (UE) 1 y 2 (sobre las cuales trata el presente artículo), y en la zona más alta (1 ha) se trazaron las UE 3 y 4 (figura 3).

La UE 1 tiene un área de $12 \mathrm{~m}^{2}$ y una profundidad máxima de 90 centímetros. En ella se recuperaron 14.400 fragmentos cerámicos, todos asociados con la ocupación tardía y de los cuales el 98,8\% son de uso cotidiano y el restante 1,2\% corresponde a material refractario utilizado en el trabajo metalúrgico (Llanos 2001).

En los primeros 15 centímetros de profundidad (horizontes A1 y A2) se registró la mayor concentración de material cultural, el cual está asociado a un área de vivienda de planta circular (6 $\mathrm{m}^{2}$ de diámetro). Hacia el centro de esta área se identificó un rasgo de forma ovoide, taqueado con desechos arqueológicos y de 


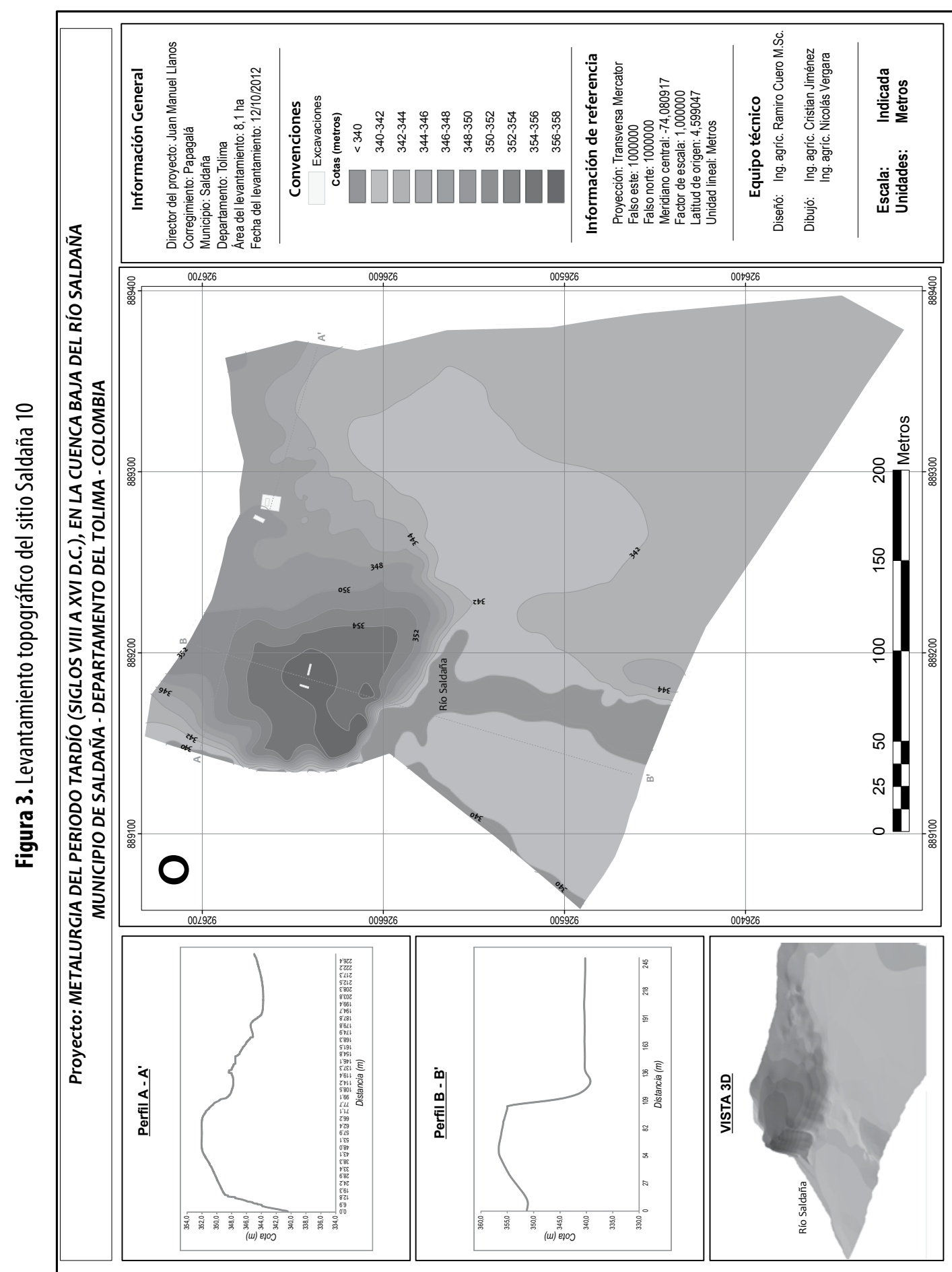


matriz negra (10 YR 2/2); en la base de este pozo se halló una urna funeraria de forma globular "matada" a manera ritual y cubierta con un casquete que hacía las veces de tapa (Llanos 2001). No fue posible realizar una datación absoluta, pero la presencia de huesos de vaca (Bostaurus), con claras evidencias de corte, permiten suponer que la depositación se dio a mediados del siglo XVI, periodo durante el cual estos animales fueron introducidos a la región por las huestes españolas (Simón [1626] 1981)

En los horizontes $\mathrm{Ab}_{1}$ y $\mathrm{Ab}_{2}$ (25-70 centímetros de profundidad) se encontraron las mayores concentraciones de fragmentos refractarios, agrupados en pequeños rasgos poco profundos (de 10 a 15 centímetros) y revueltos con cerámica de uso doméstico e instrumentos líticos; en algunas ocasiones, estos fragmentos refractarios evidencian restos de escorias y malaquita (carbonatos de cobre). Es importante destacar la presencia de objetos de cobre (una lámina y dos anzuelos). En el nivel 14 (65-70 centímetros de profundidad), asociado a las evidencias antes descritas, se recogió suficiente carbón, con el que se obtuvo la fecha de $1000 \pm 50$ años a. P. (Beta-145685).

Las evidencias recuperadas en la UE 1, relacionadas con la fabricación de objetos de metal, no fueron suficientes para delimitar un área de actividad orfebre. Durante la búsqueda de esta, se trazó la UE 2 a 4 metros de la anterior, hacia el sur (figura 3). En esta nueva excavación, de $80 \mathrm{~m}^{2} \mathrm{y}$ una profundidad máxima de 120 centímetros, se recuperó un total de 143.457 fragmentos cerámicos asociados con la ocupación tardía y de los cuales el 98,2\% son de uso cotidiano y el restante $1,8 \%$ son refractarios (figura 4 ).

En los horizontes A1 y A2 (0-25 centímetros de profundidad) de la UE 2 se registró la ocupación más intensa del sitio, y se corresponde con la mayor concentración de cerámica refractaria, muy fragmentada y erosionada (figura 4). En estos primeros niveles, el rasgo arqueológico más destacado es el basurero de una vivienda (45 centímetros de profundidad y 50 centímetros de ancho máximo), con concentración de cerámica de uso cotidiano, rocas con evidencias de exposición al fuego y herramientas líticas.

La primera área de actividad metalúrgica se localizó en el costado occidental de la excavación, sobre la planta del nivel 7 (transición horizonte A2-Ab ); su base cuadrada, de aproximadamente $2,5 \mathrm{~m}^{2}$, tenía una estructura muy cementada y se encontraba delimitada por cuatro huellas de poste. En el espacio circundante (aprox. $8 \mathrm{~m}^{2}$ ), se hallaron porciones de suelo calcinado con abundante carbón, escorias, cerámica refractaria, concreciones de arcilla con adherencias metálicas y concentraciones irregulares de cerámica de uso cotidiano y herramientas líticas (figura 5). Una muestra de carbón tomada en este lugar arrojó una edad de $780 \pm 30$ años a. P. (Beta-343649). 
Figura 4. Perfil oriental UE 2, sitio Saldaña 10, finca Gibraltar, vereda Papagalá

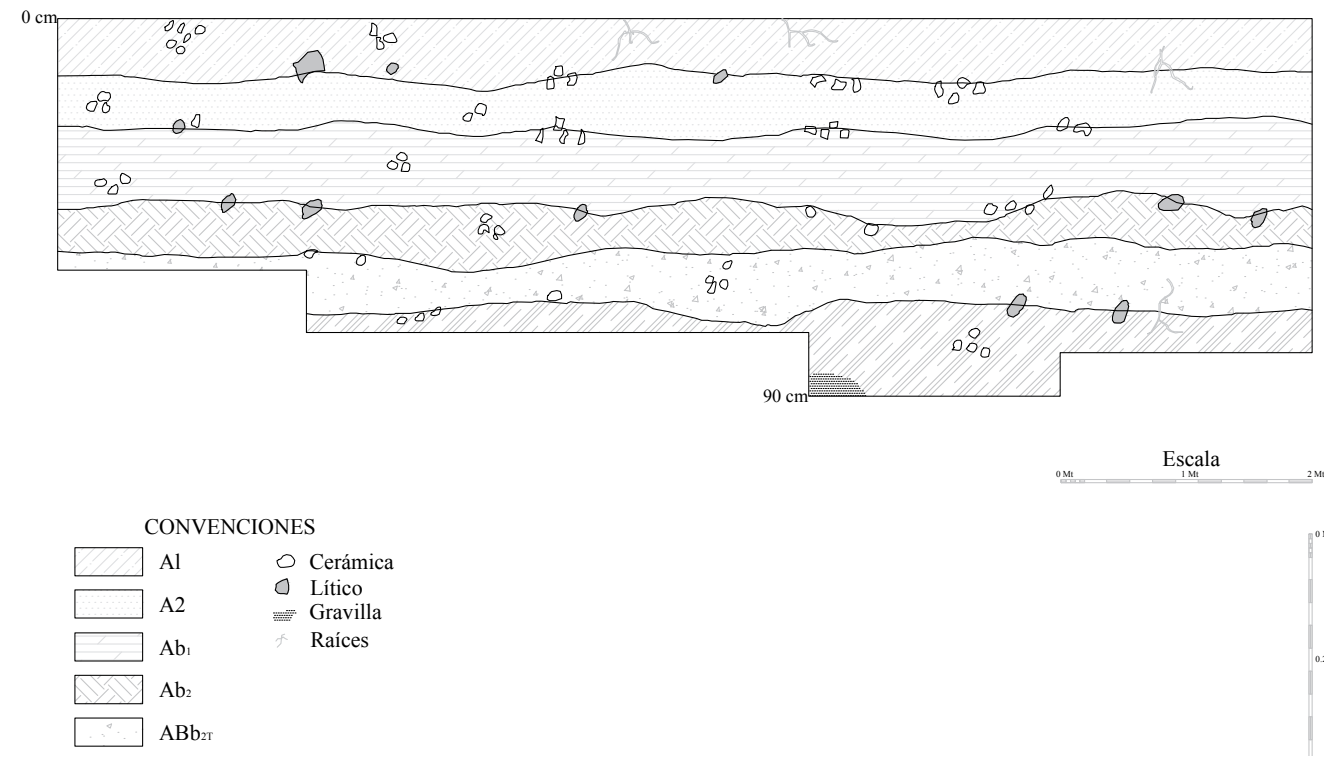

Fuente: Dibujo de Sandra Gutiérrez Abella.

Figura 5. Área de actividad metalúrgica, UE 2, nivel 35-40 centímetros de profundidad

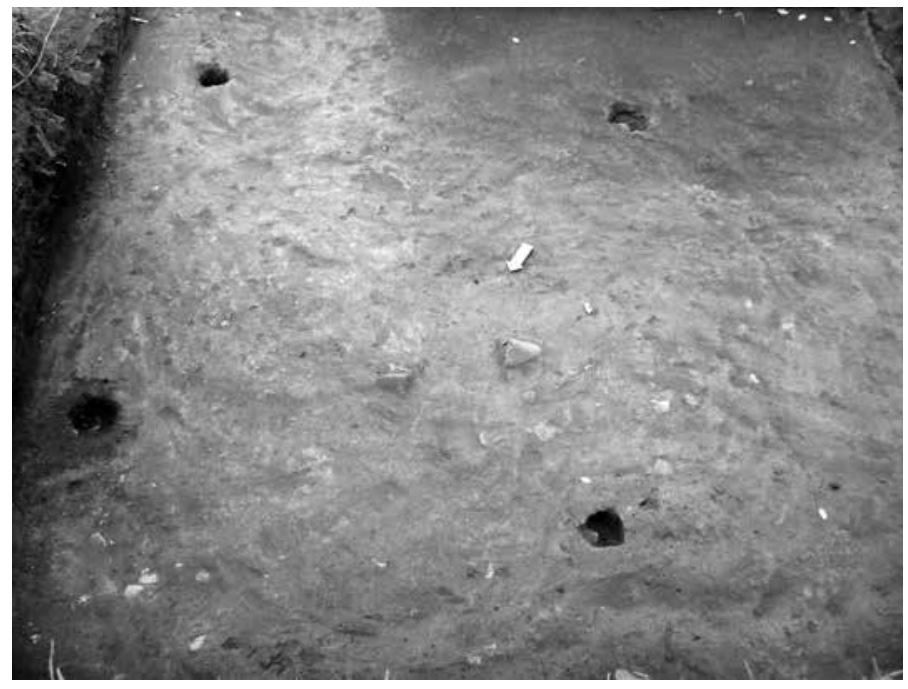

Fuente: Fotografía de Juan Manuel Llanos. 
Figura 6. Área de actividad metalúrgica y concentración de forma semicircular UE 2, nivel 45-50 centímetros de profundidad

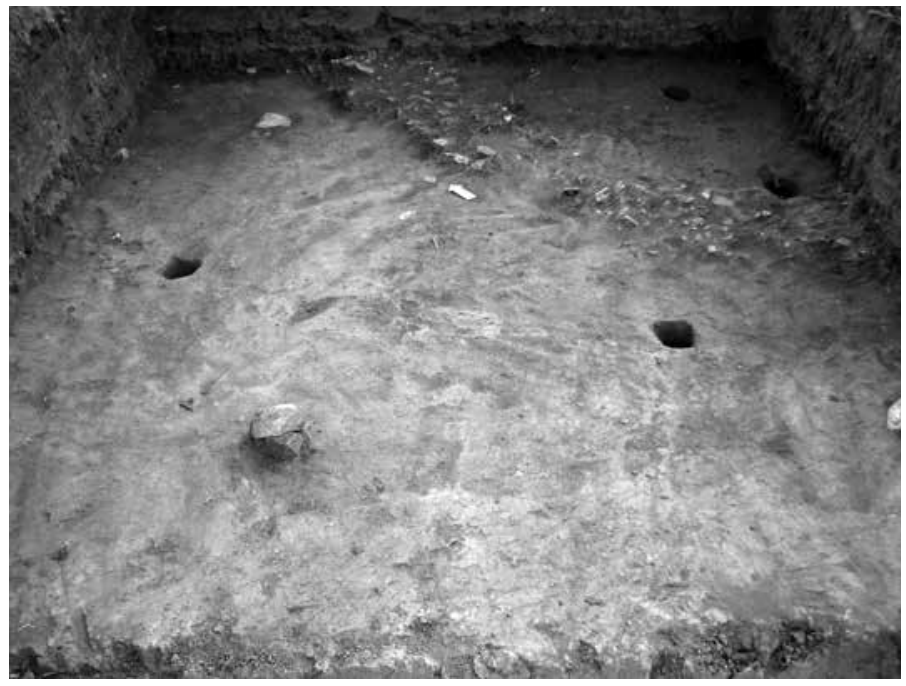

Fuente: Fotografía de Juan Manuel Llanos.

Hacia el costado norte de la excavación, en el nivel 10 (45-50 centímetros de profundidad) apareció una nueva estructura de $3 \mathrm{~m}^{2}$ aproximadamente, conformada por 5 huellas de poste que delimitan un espacio irregular, claramente dividido por una concentración semicircular de 20 centímetros de ancho, de cerámica doméstica, fragmentos refractarios, herramientas líticas, escorias y abundante carbón (figura 6).

Alrededor del área de actividad metalúrgica antes mencionada, se encontraron diferentes estructuras de combustión, dispersas en un área de $16 \mathrm{~m}^{2}$; la primera de ellas, de forma cilíndrica, tiene una profundidad de 45-50 centímetros, 13 centímetros de alto y 14 centímetros de ancho, y está fabricada con una mezcla de arcilla, fragmentos de cerámica y cantos rodados que descansan sobre un piso de roca. En el extremo superior, en una concavidad circular de 11 centímetros de diámetro y 7 centímetros de profundidad, se encontró abundante carbón. Una muestra de este material arrojó una edad de $990 \pm 30$ años a. P. (Beta343647). En el nivel siguiente (50-55 centímetros de profundidad) y a 1,5 metros hacia el oriente, se identificó un grupo de 4 rocas con evidencias de exposición al fuego, en cuyo centro había abundante carbón (figura 7).

Otro fogón que se encontró en el nivel 12 (55-60 centímetros de profundidad) está formado por un conjunto semicircular de rocas de diferentes tamaños que presentan evidencias de exposición al fuego; estas delimitaban una 
Figura 7. Estructuras de combustión (fogones) asociadas al área de actividad metalúrgica UE 2

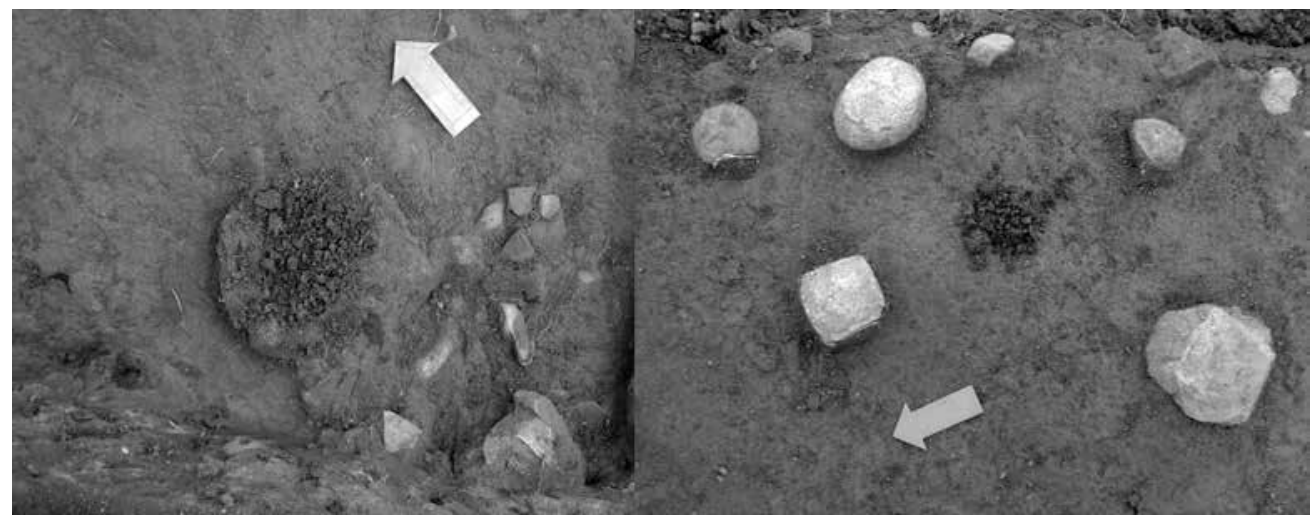

Fuente: Fotografías de Juan Manuel Llanos.

concentración de gravilla quemada mezclada con carbón. Una muestra tomada de los alrededores arrojó una edad de $1100 \pm 60$ años a. P. (Beta-185370). Es probable que la función que cumplía este “colchón” de gravilla estuviera relacionada con una distribución uniforme del aire, que ingresaba a la hoguera como resultado del empleo de sopladores (cañas huecas), lo cual permitía avivar el fuego y alcanzar mayores temperaturas, hipótesis cuya verificación requiere de un proceso experimental (figura 8).

A 3 metros hacia el oriente y asociado a este último fogón, se halló un rasgo (60-85 centímetros de profundidad) de forma irregular, matriz negra (7,5 YR 2,5/1) y taqueado con cerámica refractaria, rocas, carbón y gran cantidad de gravilla quemada. Las evidencias indican que esta estructura era el contenedor exclusivo de los desechos resultantes de las actividades metalúrgicas realizadas en el fogón antes mencionado. Esta particularidad puede responder al tipo de actividad desarrollada y tener connotaciones simbólicas y cosmológicas, las cuales llevan a "que el uso social e ideacional de algunos elementos se extienda más allá del descarte” (Politis y Jaimes 2005, 251).

En la transición de los horizontes $\mathrm{ABb}_{2 \mathrm{~T}}$ a $\mathrm{Bb}_{2 \mathrm{~T}}$ (65-70 centímetros de profundidad), hacia el costado norte de la excavación, se halló una concentración de cerámica de uso cotidiano y refractaria mezclada con abundante carbón; una muestra de este material arrojó una edad de $1140 \pm 30$ años a. P. (Beta-343648). Esta es la fecha más temprana que se tiene del establecimiento de los grupos humanos de periodo Tardío (complejo cerámico Magdalena Inciso) en el sur del departamento de Tolima. 
Figura 8. Fogón y "colchón" de gravilla, UE 2, nivel 55-60 centímetros de profundidad

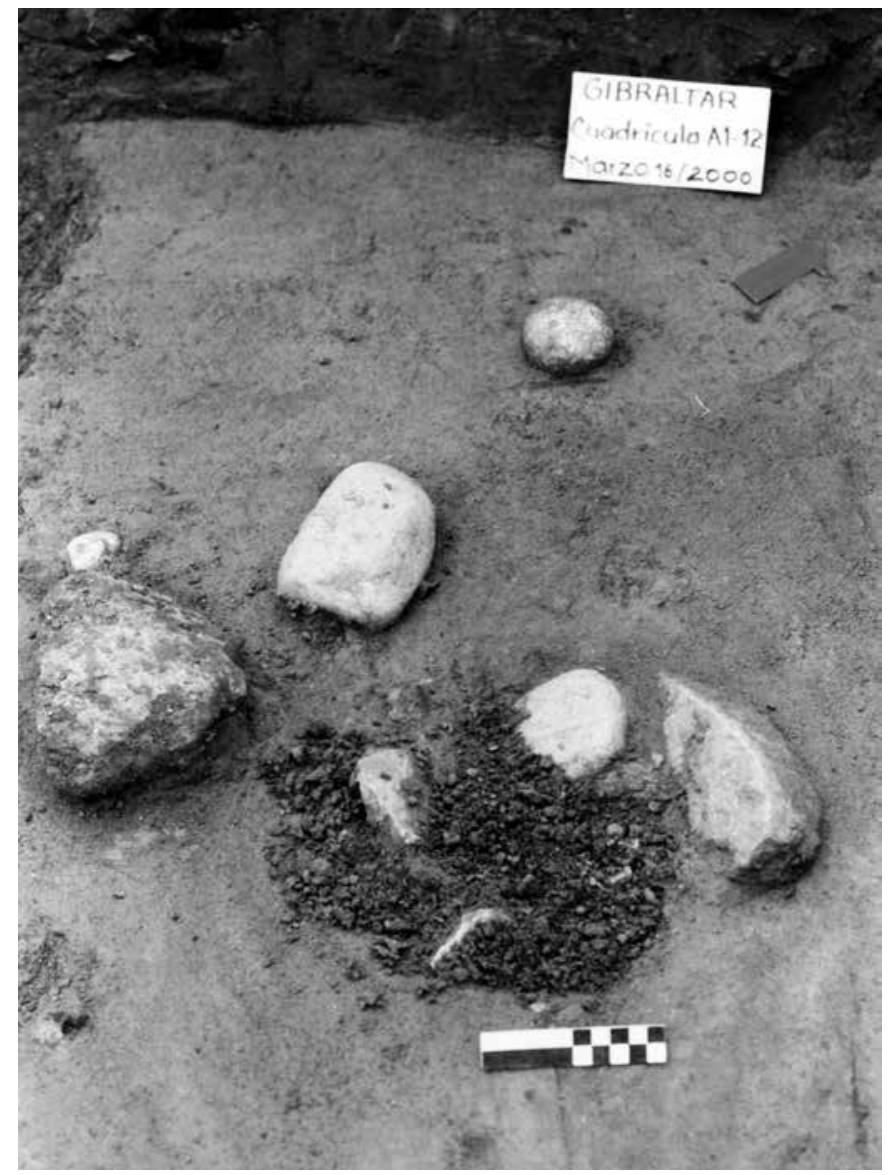

Fuente: Fotografía de Juan Manuel Llanos.

Relacionado con las áreas de actividad metalúrgica antes descritas, se halló hacia el costado sur de la excavación un sector dedicado al tallado de herramientas líticas (50-55 centímetros de profundidad), con abundante cantidad de desechos, microlascas, núcleos y percutores, entre otros elementos. En el extremo opuesto (costado norte) se recuperaron algunos huesos de tortuga (Chelonia), mamíferos (Mammalia), peces (cf. Pimelodus clarias), sapos (Anura), roedores (Rodentia) y aves sin identificar, así como cuescos de palma (Attalea butyracea) ${ }^{1}$.

El análisis arqueozoológico fue realizado por Luz Stella Rincón, antropóloga de la Universidad Nacional de Colombia, y la identificación arqueobotánica, por Gaspar Morcote Ríos, del Instituto de Ciencias Naturales de la Universidad Nacional de Colombia. 


\section{Evidencias relacionadas con el trabajo de los metales}

\section{Cerámica refractaria}

La cerámica de uso diario del complejo Magdalena Inciso del sitio Saldaña 10 no presenta grandes diferencias con respecto a la registrada en el resto de la región, para el periodo Tardío (Llanos 2001; Salgado et al. 2006, 2008). La vajilla está conformada por ollas globulares y subglobulares (30,4\%), cuencos $(10,5 \%)$, platos $(7,3 \%)$, copas $(0,3 \%)$, figurinas $(0,2 \%)$ y, en menor proporción, volantes de uso, pintaderas, vasos y pesas de red en arcilla. La pasta de esta muestra se caracteriza por tener una textura compacta y cocción en atmosfera oxidante, y el desgrasante utilizado es arena de río sin seleccionar (cuarzo, hornblenda, augita, biotita y cenizas volcánicas).

La particularidad la constituyen los fragmentos refractarios (7\%). Estos se fabricaron con arcilla de origen local, que presenta altos contenidos de cuarzo volcánico, materia orgánica, compuestos alcalinos y sales de fosfato. Como desgrasante se adicionó arena de río muy fina, con altos contenidos de feldespato, cuarzo, carbón y tejidos vegetales, particularidades que le confieren propiedades refractarias (González 2004). Es notorio que las inclusiones (desgrasante) lucen mecánica y artificialmente disgregadas, es decir, mientras en uno de sus lados tienen bordes entre subangulares y subredondeados y redondeados, producto del rodamiento, en el otro se reconocen superficies rotas e irregulares ${ }^{2}$. Los artesanos escogieron el atemperante mediante el empleo de métodos mecánicos, posiblemente cerniendo los sedimentos del río con canastos elaborados en fibras vegetales, con el propósito de separar la arena fina; luego le agregaron cuarzo triturado o molido. Estas características son una muestra de la elección tecnológica realizada por los artesanos prehispánicos. Es importante mencionar que a 10 metros de la excavación se ubicó un depósito de arcilla con las propiedades antes descritas. En la actualidad, el material que de allí se extrae es utilizado para recubrir hornos donde se cocinan los alimentos ${ }^{3}$.

\footnotetext{
2 Las secciones delgadas y los análisis mineralógicos de los materiales refractarios se realizaron en el Laboratorio de Ciencias de la Conservación de la Universidad Externado de Colombia y en el Departamento Técnico Industrial del Museo del Oro.
}

3 Análisis mineralógico realizado en el Laboratorio Nacional de Suelos del Instituto Geográfico Agustín Codazzi (IGAC). 
La técnica de fabricación fue el modelado y la temperatura máxima de cocción fue de $500^{\circ} \mathrm{C}$, como lo señala la presencia de fragmentos orgánicos, como madera carbonizada, restos de plantas, carbón y materia orgánica microscópica, en medio de un ambiente inicialmente reductor que, hacia el final del proceso, se volvía oxidante. La pasta es de color negro y ambas caras se encuentran alisadas; en la interna, que es altamente porosa, son comunes las manchas de óxidos de hierro, ya que estuvo expuesta a mayores temperaturas, como lo indica la destrucción u oxidación de la materia orgánica parcialmente piritizada y levemente oxidada ${ }^{4}$. La superficie externa es porosa y presenta un baño ( 2 a 5 milímetros de espesor) de color claro alisado; esta configuración permite la salida de los gases tóxicos, resistir las altas temperaturas y conservar el calor (Sáenz et al. 2007).

Las formas características de este conjunto son las siguientes: moldes abiertos, bivalvos y para fundición a la cera perdida $(7,6 \%)$, crisoles $(2 \%)$, embudos $(1,5 \%)$, soportes troncocónicos $(0,9 \%)$, conductos $(0,4 \%)$, tapones $(0,07 \%)$ y fragmentos amorfos (87,5\%); algunos se encuentran total o parcialmente vitrificados.

En algunos fragmentos de molde se observan conductos empleados como respiraderos, diseñados para el ingreso y la distribución del metal fundido; en la cara interna de estas piezas se conservan huellas que permiten identificar los objetos fabricados en este taller: cuentas, cordones, pectorales acorazonados, figuras antropomorfas y zoomorfas con extremidades en escuadra, entre otros (figura 9). Al reconstruir las formas originales fue posible identificar un tipo de molde que se conoce con el nombre de crisol-molde (Sáenz et al. 2007).

Los crisoles se caracterizan por tener una base gruesa y forma de cuenco y por carecer de vertederas, cinturas o apliques para transportarlos; en este caso, es posible que los artesanos prehispánicos utilizaran tenazas fabricadas con ramas verdes, lo cual retardaría los efectos del calor (figura 9) (González 2004).

Otra de las formas representativas son los soportes troncocónicos con base ancha; el extremo opuesto de la base es angosto y presenta un canal en $v$ para encabar los moldes durante el proceso de vaciado o calentado, dentro o fuera de la hoguera. El uso de patas de diferente tamaño permite tener cierta inclinación que favorece la distribución rápida y uniforme del metal fundido durante el vertimiento gracias a la gravedad (figura 10). En ocasiones, estas piezas se encuentran integradas a los moldes, conservan rastros de hollín y evidencias de vitrificación.

4 Descripción petrográfica de la cerámica realizada en el Laboratorio de Ciencias de la Conservación de la Universidad Externado de Colombia. 
Figura 9. 1) Molde antropomorfo vaciado a la cera perdida; 2) molde zoomorfo de extremidades en escuadra; 3) molde de pectoral acorazonado; 4-5) crisoles, y 6) embudo ${ }^{5}$

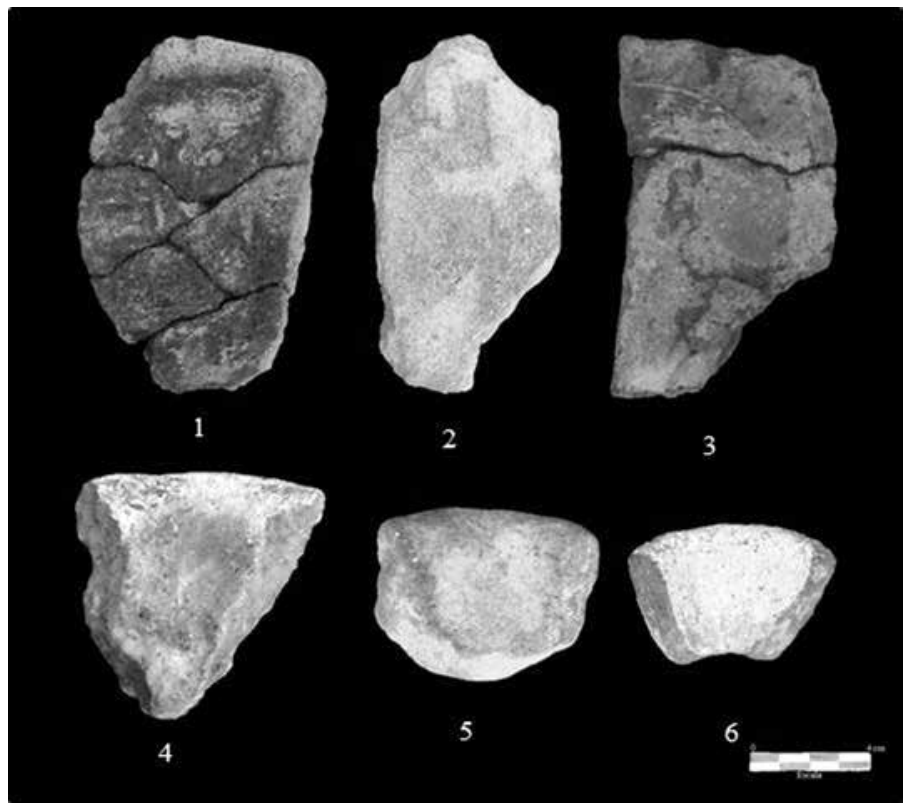

Fuente: Fotografías y montaje de Juan Manuel Llanos.

Figura 10. Reconstrucción de la forma de uso de los soportes troncocónicos ${ }^{6}$

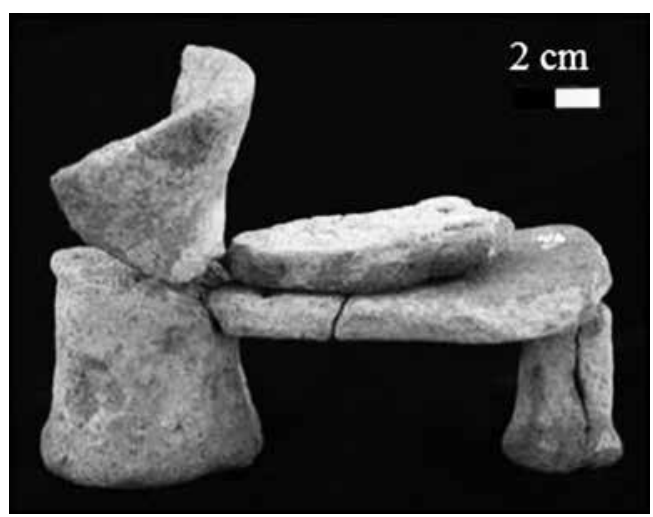

Fuente: Fotografía de Pablo Obando.

5 En la cara interna de este embudo se hallaron dos gotas de oro atrapadas entre los poros, las cuales fueron identificadas por Roberto Lleras Pérez.

6 Comunicación personal con Pablo Obando, restaurador del Departamento Técnico Industrial del Museo del Oro. 
Figura 11. Hornilla recuperada en la cuadrícula UE 2, nivel 15-20 centímetros de profundidad

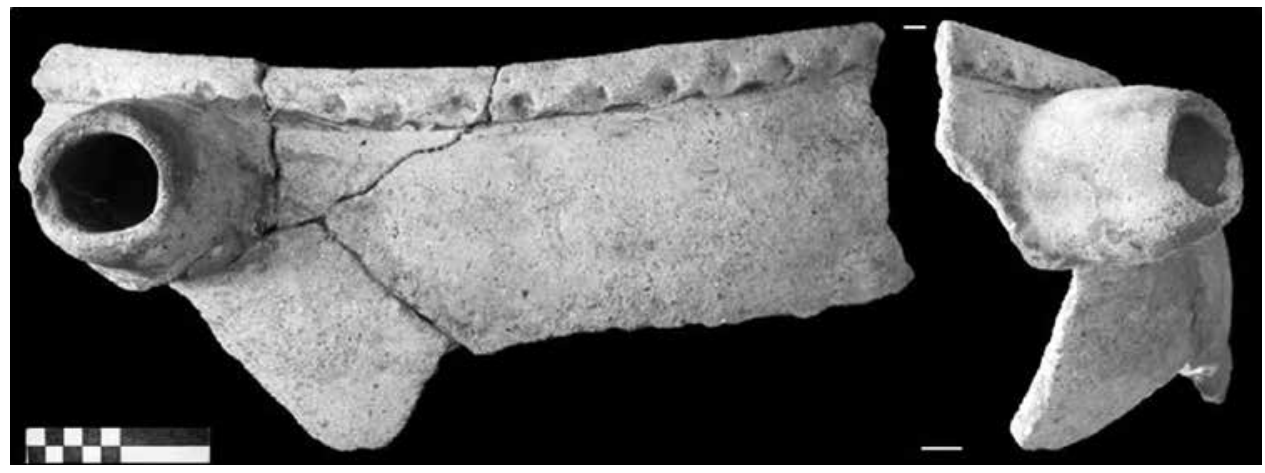

Fuente: Fotografias y montaje de Juan Manuel Llanos.

Es importante mencionar numerosos fragmentos de hornilla recuperados en las UE 1 y 2, con características propias de la cerámica de uso cotidiano. Esta vasija tiene forma de cuenco con borde invertido y reforzado externo, decorado con presionados ungulares y 2 vertederas tubulares opuestas, ubicadas en el hombro de la pieza y levemente inclinadas en ángulo de $45^{\circ}$ con respecto a la línea imaginaria de la boca, que tiene un diámetro de 24 centímetros. En estos conductos se disponían cañas huecas utilizadas como sopladores, con la intención de avivar el carbón que se encontraba en el interior de la olla y así alcanzar mayores temperaturas (figura 11). Una pieza similar se encuentra expuesta en el Museo del Oro Quimbaya.

\section{Herramientas líticas}

De los 27.542 elementos líticos recuperados en las excavaciones, el 0,6\% tiene características morfológicas (tamaño y forma perimetral), peso (100-700 gramos), dureza (+ de 5 escala de Mohs), acabado superficial (alisado, pulido o bruñido) y huellas de uso (alisados, bruñidos, escamados, picados y desconchados), que permiten asociarlos con las diferentes etapas de la producción de objetos de metal; también, con la molienda de menas, fabricación, decoración y acabado (Carcedo 1998; Carcedo y Vetter 2002; Shimada 1987). Todas estas pautas se complementaron con la información contextual.

Las herramientas líticas identificadas son las siguientes: alisadores (37,3\%), martillos (16,8\%), punzones (18,7\%), manos (3,8\%), embutidores $(0,6 \%)$, placas alisadas (11,6\%), yunques (9,6\%) y morteros (1,3\%). Los talladores prehispánicos 
seleccionaron materias primas de origen local: rocas ígneas (basaltos, diabasas y granito), sedimentarias (chert) y muy pocas metamórficas (cuarcita y mineral de cuarzo lechoso) (figura 12) .

Figura 12. 1) Martillo; 2) cincel; 3) martillo-alisador; 4) doblador; 5) pulidor; 6) embutidor

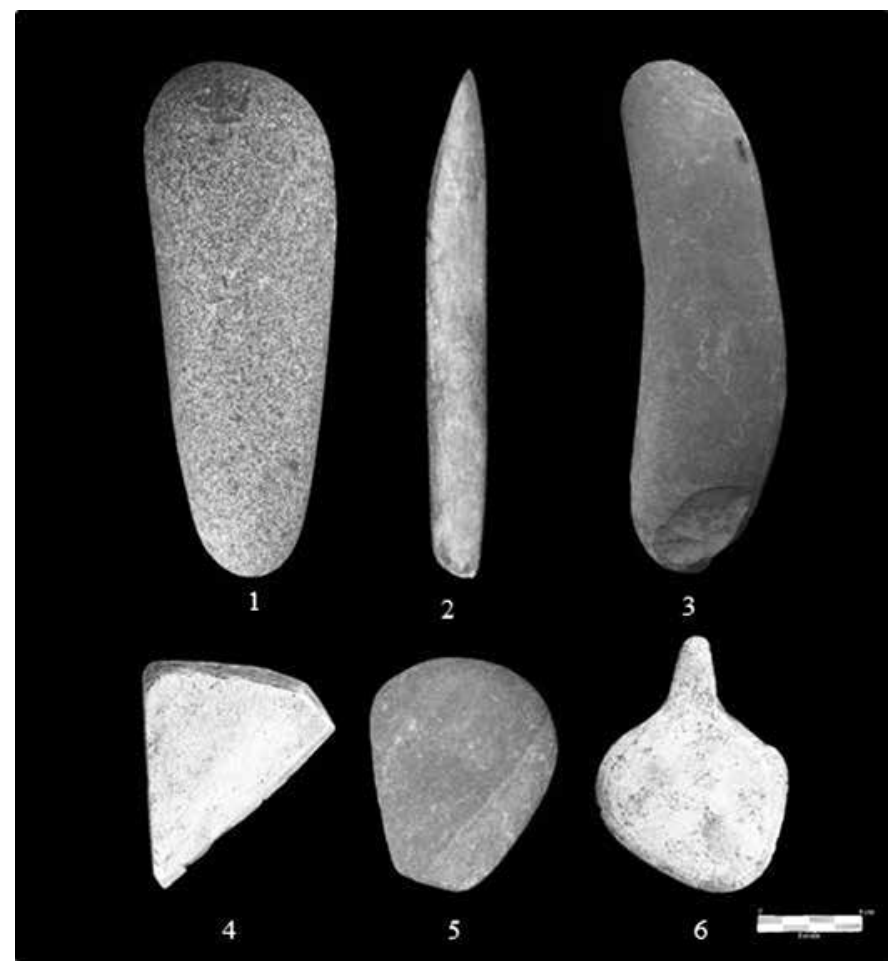

Fuente: Fotografías y montaje de Juan Manuel Llanos.

\section{Otras evidencias del trabajo orfebre}

En la UE 2 se recuperaron 265 fragmentos amorfos de arcilla cocida; en algunos de ellos se observan adherencias metálicas (carbonatos de cobre), huellas de dedos, superficies alisadas intencionalmente y canales paralelos; se encuentran asociados a fogones y concentraciones de cerámica refractaria. La presencia de mullita indica que estuvieron expuestos o se cocieron a temperaturas que

7 Identificación litológica (herramientas líticas) realizada por el Laboratorio de Geología de la Universidad del Tolima, Facultad de Ingeniería Agronómica. 
oscilaron entre los $980^{\circ} \mathrm{C}$ y los $1.000^{\circ} \mathrm{C}$, lo anterior debido a que las arcillas caoliníticas, al llegar a temperaturas por encima de los $980^{\circ} \mathrm{C}$, comienzan a formar este minera $l^{8}$. No se tiene certeza sobre su función; posiblemente fueron parte de hornos o empleados para revestir superficies próximas a las áreas de actividad metalúrgica (figura 13).

Figura 13. Concreciones con canales paralelos y adherencias metálicas (azurita)

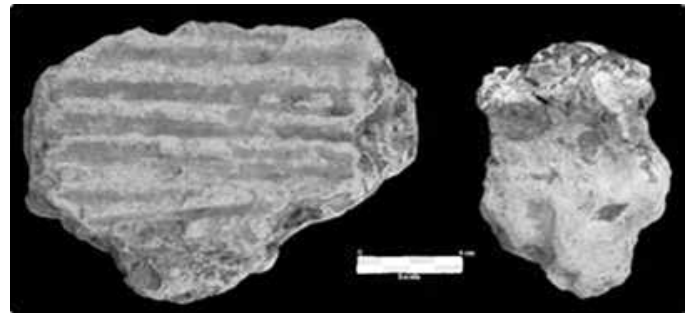

Fuente: Fotografías y montaje de Juan Manuel Llanos.

Es común encontrar en los fragmentos de cerámica refractaria adherencias de óxido de hierro (hematita) o fosfatos de calcio (ceniza o huesos) o potasio, a manera de una delgada capa de color blanco o gris claro en la cara interna. La hematita se agrega a la carga de los crisoles para facilitar la separación de la escoria y el metal (fundente) (Epstein y Shimada 1983); los fosfatos pueden ser utilizados como desmoldantes o para proteger la superficie de los moldes y crisoles contra la acción erosiva del metal fundido (Angiorama 2004; González 2007).

Un hecho que llama la atención en la excavación del sitio Saldaña 10 es el escaso número de escorias recuperadas (27 elementos), situación que puede estar relacionada con tres factores: la pureza de las menas utilizadas, la molienda de estas en búsqueda de gotas de metal atrapadas para ser refundidas y la baja densidad que genera el uso de carbonatos de cobre (González 2004).

\section{Consideraciones finales}

Durante algo más de ochocientos años (siglos IX-XVII d. C.), los ocupantes del sitio Saldaña 10 fabricaron objetos de metal para propósitos utilitarios (anzuelos) y

8 Resultados del análisis microscópico y metalográfico realizado en el Laboratorio de Ciencias de la Conservación de la Universidad Externado de Colombia. 
ornamentales (pectorales acorazonados, narigueras, cuentas de collar, figuras antropomorfas y zoomorfas). Ellos aprovecharon los recursos locales para diseñar y crear una variedad de moldes, soportes, crisoles, embudos y tapones, en arcillas de origen local con propiedades refractarias $\left(>1.200^{\circ} \mathrm{C}\right)$, acrecentadas intencionalmente. De la misma manera, explotaron las fuentes litológicas (ígneas, sedimentarias y metamórficas) de acuerdo con sus propiedades físicas (dureza) para fabricar las herramientas necesarias (figura 14).

Figura 14. Diagrama del modelo de producción de objetos de metal en el sitio Saldaña 10, valle del río Magdalena, departamento del Tolima, siglos VIII-XVIII d. C.

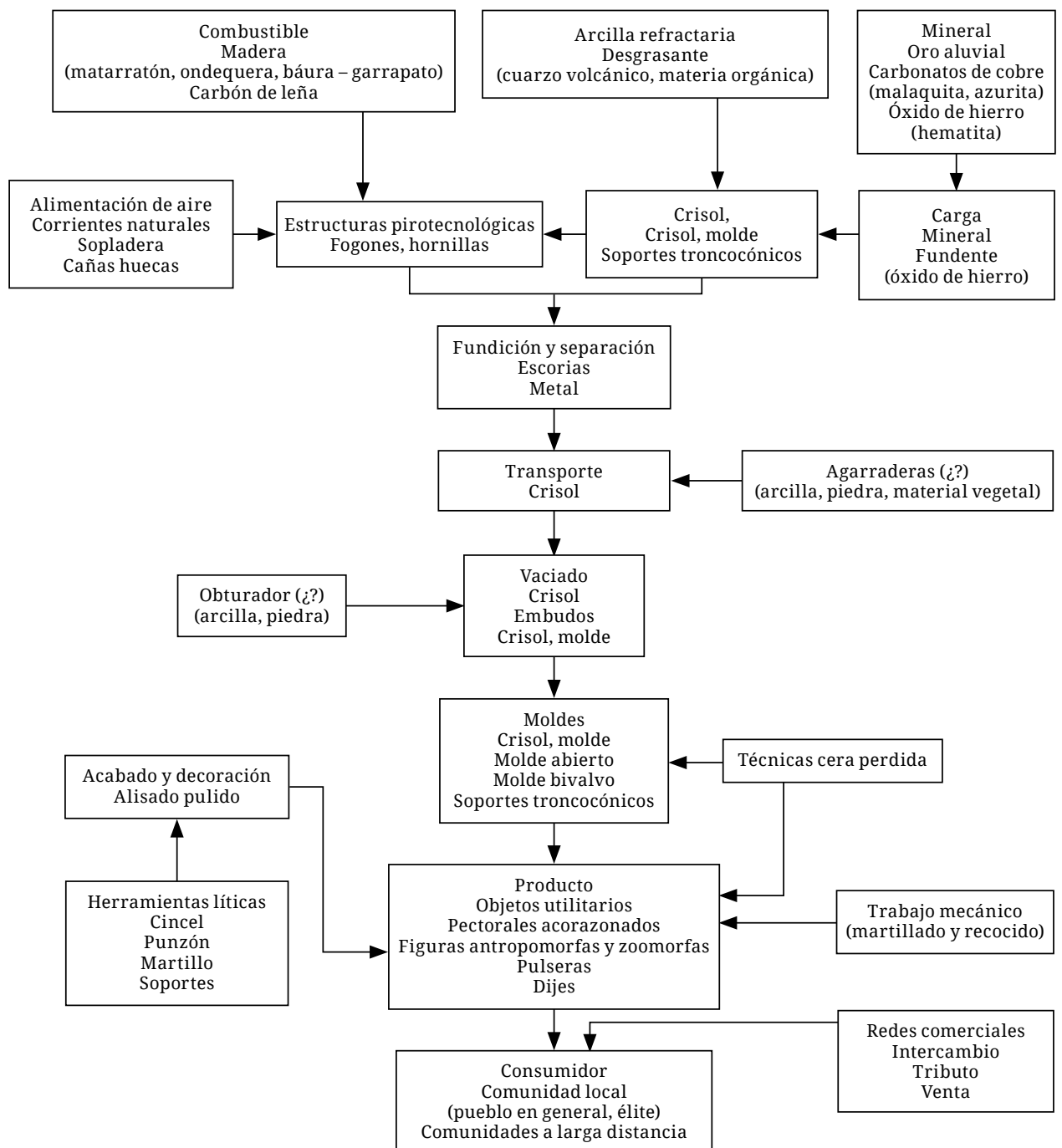

Fuente: Elaboración propia. 
El trabajo continuado les permitió a los orfebres adquirir destreza en el manejo de diferentes técnicas de fabricación y acabado de los objetos de metal: martillado-recocido (mecánico), vaciado a la cera perdida y decoración repujada y gravada. Supieron cómo aprovechar los recursos forestales de alto potencial calórico (el matarratón, la ondequera y el báura-garrapato) que les ofrecía el medio para alimentar sus fogones. Emplearon cañas huecas y sopladores fabricados en fibras vegetales, y se valieron de las corrientes de aire naturales para alcanzar temperaturas que rondaban los $1.200^{\circ} \mathrm{C}$; para iniciar el fuego es posible que utilizaran excremento animal (rumiantes), termiteros secos o desechos orgánicos, como se constató durante la observación etnoarqueológica (figura 14).

Los metales empleados por estos artesanos fueron el cobre y el oro, aunque no se puede descartar el uso de aleaciones como la tumbaga. Ricas vetas de cobre se encuentran en el piedemonte de la cordillera Central, distantes del sitio entre 25 kilómetros y 61 kilómetros, como resultado de la influencia volcánica (Mutis 1993); el oro lo podían obtener mediante el barequeo (mazamorreo) en las riberas del Saldaña y sus afluentes, tal como lo hacen las comunidades actuales.

Los orfebres precolombinos ubicaron los talleres metalúrgicos en la parte baja de la terraza, hacia el costado sur (UE 2), con el fin de aprovechar las corrientes de aire naturales que corren de forma paralela al curso del río Saldaña. La forma básica estaba constituida por una enramada, posiblemente sin paredes y de base cuadrada, donde se realizaba el vaciado, el enfriamiento del molde, la extracción de la pieza (fractura del molde) y el acabado (pulido, bruñido y decorado). Al mismo tiempo, en el área circundante, a pocos metros, se encontraban las estructuras pirotecnológicas (fogones, suelo quemado, hornillas) requeridas en la fundición de los metales mediante el empleo de crisoles o crisoles-molde, y fragmentos de herramientas líticas (martillos y placas) utilizadas en el beneficio o refinamiento (figura 14).

Comenzando el siglo IX d. C. (1140 \pm 30 años a. P.), se estableció en una zona próxima a las viviendas el primer taller metalúrgico en el sitio, cuya área total aproximada era de $20 \mathrm{~m}^{2}$, de los cuales $3 \mathrm{~m}^{2}$ estuvieron ocupados por la enramada y los restantes $17 \mathrm{~m}^{2}$ se utilizaron para ubicar las estructuras de combustión; los desechos se depositaron en pequeños basureros de forma irregular ubicados en los alrededores. Durante un periodo que se extiende por lo menos 150 años, entre los inicios del siglo IX d. C. y el final del X d. C., este espacio no sufrió trasformaciones significativas.

A mediados del siglo XII d. C. (780 \pm 30 años a. P.) se registran algunas transformaciones: el área total del taller se reduce casi a la mitad, la enramada es más pequeña (aprox. 2,5 m²), al igual que el espacio circundante (aprox. $8 \mathrm{~m}^{2}$ ), 
donde se encuentran porciones de suelo calcinado y fogones. Durante este periodo, que se extiende hasta el abandono del sitio, a mediados del siglo XVII d. C., las viviendas rodean la zona destinada al trabajo metalúrgico, por lo cual se puede pensar que, para ese momento, el taller hizo parte de la unidad residencial. Otras novedades que se dieron durante esta época son el empleo de hornillas y el uso de moldes abiertos y bivalvos.

Entre el grupo de objetos de metal que se fabricaban en el sitio es importante destacar las figuras con extremidades en escuadra que, de acuerdo con comparaciones estilísticas e iconográficas, han sido asociadas al periodo Clásico Regional (0-700 d. C.) (Salgado y Llanos 2010) o estilo Tolima temprano (Mendoza 2010). Pero los contextos donde se excavaron los moldes empleados en la fabricación de este tipo de objetos, fechados entre el siglo IX d. C y el X d. C., ponen en evidencia, una vez más, que determinadas características o variables empleadas para definir estilos o tradiciones metalúrgicas no se circunscriben a periodos y territorios rígidamente delimitados (Lleras 2007b) (figura 14).

Es poco probable que los artesanos se dedicaran de manera exclusiva al trabajo de los metales; se convirtieron más bien en "especialistas a tiempo parcial” (Bernier 2008). Los orfebres fueron un segmento de la población con conocimientos y habilidades especializados, que fueron requeridos, en determinados momentos, bien fuera por el círculo familiar, bien por la comunidad o personajes con estatus (jerarquía) dentro del grupo, lo cual les posibilitaba cierta autonomía, en cuanto podían liberarse de forma parcial de las obligaciones relacionadas con la subsistencia. Los orfebres realizaron este trabajo durante un largo periodo, lo que les permitió experimentar e innovar, generar nuevos conocimientos y desarrollar mayores destrezas que se transmitieron de generación en generación, hasta alcanzar cierto grado de especialización.

Cabe considerar el alto valor cultural y simbólico que tenía una actividad como la orfebrería, en la que los artesanos actuaban como transformadores (chamanes) de elementos naturales (mineral-metal) por medio del fuego y del trabajo, en una forma culturalmente significante (Lleras 2007b; Reichel-Dolmatoff 1988). El trabajo artesanal, en muchas sociedades tradicionales, es considerado mucho más que el dominio de una técnica de manufactura, en la medida en que los procesos de producción material están inmersos en complejos rituales que incluyen aspectos cosmológicos y cosmogónicos (Uceda 2010).

El funcionamiento del taller metalúrgico del sitio Saldaña 10 tiene elementos en común con otros reportados en Suramérica, como el caso de Rincón Chico y Los Amarillos en el noroeste argentino (Angiorama y Taboada 2007; González 2010), en cuanto a la dedicación parcial y a la multifuncionalidad de los 
artesanos, la relación directa entre las áreas de actividad orfebre y las residenciales, la escala de producción (pequeña y mediana) y la clase de objetos fabricados que serían destinados para uso de toda la comunidad.

\section{Agradecimientos}

El presente proyecto de investigación contó con el apoyo incondicional de numerosas personas, sin las cuales no hubiera sido posible llevarlo a feliz término: en el municipio de Saldaña, especialmente, de la familia Arias y del señor Gregorio Arias, de Héctor Llanos Vargas, Sandra Gutiérrez Abella, Pablo Obando, Juanita Sáenz Samper, Gustavo G. Politis y Roberto Lleras, quienes siempre creyeron en mí y en el proyecto y supieron apoyarme, orientarme y corregirme durante este largo proceso. No menos importante es el apoyo incondicional brindado por los miembros de mi familia: Nidia Chaparro Cuervo, Germán Llanos Vargas, Isabel Llanos Chaparro, Mónica Fernanda Tovar y, muy especialmente, Juana Llanos Tovar, mi pequeña hija, quien entendió mis ausencias y desesperos y, a pesar de ellos, nunca dejó de sonreír. De igual manera, agradezco a Héctor Galeano Arbeláez y a Jairo González.

\section{Referencias}

Angiorama, Carlos. 2004. "Acerca de incas y metales en Humahuaca. Producción metalúrgica en los Amarillos en tiempos del Tawantinsuyu". Relaciones de la Sociedad Argentina de Antropología 29: 39-58.

Angiorama, Carlos y Carmenza Taboada. 2007. "Producción metalúrgica en un contexto doméstico de los amarillos (JujuyArgentina)”. En Lleras 2007a, 409-420.

Bernier, Hélène. 2008. "La especialización artesanal en el sitio Huacas de Moche: contextos de producción y función sociopolítica”. En Castillo et al. 2008, 33-51.

Carcedo, Paloma. 1998. "Instrumentos utilizados en la manufactura de piezas metálicas precolombinas que se encuentran en los museos”. Boletín Museo del Oro 44-45: 241-270.

Carcedo, Paloma y Luisa Vetter. 2002. "Instrumentos utilizados para la fabricación de piezas de metal para el periodo inca”. Baessler-Archiv 50: 47-66.

Castillo, L. et al., eds. Actas de la Primera Conferencia Internacional de Jóvenes Investigadores sobre la Sociedad Mochica. Lima: IFEA; Pontificia Universidad Católica del Perú; Dumbarton Oaks y Museo Larco Herrera.

Duque Gómez, Luis. 1964-1966. Exploraciones arqueológicas en San Agustín. Bogotá: Instituto Colombiano de Antropología (ICAN). 
Epstein, Stephen e Izumi Shimada. 1983. "Metalurgia sicán: una reconstrucción de la producción de la aleación de cobre en el Cerro de los Cementerios, Perú". Beiträge zur Allgemeinen und Vergleichenden Archäologie 5: 379-430.

Fraresso, Carlos. 2008. "El sistema técnico de la metalurgia de transformación en la cultura mochica: nuevas perspectivas”. En Arqueología mochica: nuevos enfoques, editado por L. Castillo et al., 153-171. Lima: PUCP; IFEA.

González, Luis. 2004. Bronces sin nombre. La metalurgia prehispánica en el noroeste argentino. Buenos Aires: Fundación Ceppa.

—. 2007. "Recuerdos del bronce. La metalurgia prehispánica tardía en el noroeste argentino”. En Lleras 2007a, 25-52.

-. 2010. "Fuegos sagrados. El taller metalúrgico del sitio 15 de Rincón Chico (Catamarca, Argentina)”. Boletín del Museo Chileno de Arte Precolombino 15 (1): 47-62.

\section{Graffam, Gray, Álvaro Carevic y Mario} Rivera. 1997. "Evidencias metalúrgicas de fundición de cobre en el sitio formativo tardío de Ramaditas, quebrada de Guatacondo, provincia de Iquique, Chile”. Estudios Atacameños 12: 47-59.

Lechtman, Heather. 1977. "Style in Technology: Some Early Thoughts”. En $M a-$ terial Culture: Styles, Organization, and Dynamics of Technology, editado por H. Lechtman y R. S. Merrill, 3-20. St. Paul: West Publishing.

Lemonnier, Pierre. 1986. "The Study of Material Culture Today: Toward an Anthropology of Technical Systems". Journal of Anthropological Archaeology 5: 147-186.

\section{-.1992. Elements for an Anthropology of} Technology. Anthropological Papers 88. Ann Arbor: Museum of Anthropology, University of Michigan.
Llanos, Juan Manuel. 2001. "Pautas de asentamiento prehispánicas en la cuenca baja del río Saldaña (Saldaña-Tolima)”. Boletín de Arqueología 16 (2): 3-66.

Llanos, Juan Manuel y Sandra Gutiérrez. 2006. "Bajo el sol abrasador de las llanuras de Coyaima: aproximaciones a la historia prehispánica del valle del Magdalena tolimense”. Maguaré 20: 177-200.

Lleras, Roberto, comp. 2007a. Metalurgia en la América antigua. Teoría, arqueología, simbología y tecnología de los metales prehispánicos. Bogotá: Fundación de Investigaciones Arqueológicas Nacionales, Banco de la República; Instituto Francés de Estudios Andinos (IFEA).

—. 2007b. "La metalurgia prehispánica en el norte de Suramérica: una visión de conjunto”. En Lleras 2007a, 129-159.

—. 2011. Comunicación personal. 25 de mayo.

Mendoza, Sandra. 2010. "Animales fantásticos. Fauna mítica en las cálidas riberas del río Magdalena”. En El Tolima milenario, un viaje por la diversidad, editado por Héctor Salgado, 121-135. Ibagué: Universidad del Tolima; Museo del Oro, Banco de la República.

Mutis, Vicente. 1993. Catálogo de los yacimientos, prospectos y manifestaciones minerales de Colombia. Publicaciones Geológicas Especiales de Ingeominas 13. Bogotá: Ingeominas.

Patiño, Diógenes. 1997. "Arqueología y metalurgia en la costa pacífica de Colombia y Ecuador". Boletín Museo del Oro 43: 49-67.

Pérez de Barradas, José. 1958. Orfebrería prehispánica de Colombia: estilos Tolima y Muisca. Vol. 2. Bogotá: Banco de la República.

Politis, Gustavo y Arturo Jaimes. 2005. "Patrones de descarte entre los hoti del Amazonas venezolano”. En Etnoarqueo- 
logía. El contexto dinámico de la cultura material a través del tiempo, editado por E. Williams, 237-265. Colección Debates. México: Colegio de Michoacán.

Reichel-Dolmatoff, Gerardo. 1988. Orfebrería y chamanismo: un estudio iconográfico del Museo del Oro. Bogotá: Banco de la República; Colina.

Rengifo, Carlos y Carol Rojas. 2008. “Talleres especializados en el complejo arqueológico Huacas de Moche: el carácter de los especialistas y su producción”. En Castillo et al. 2008, 325-340.

Sáenz, O. Juanita et al. 2007. "Tras las huellas de los orfebres: herramientas para la metalurgia en las sociedades tempranas del Valle del Cauca”. En Lleras 2007a, 363-408.

Salgado, Héctor et al. 2006. Antiguos pobladores en el valle del Magdalena tolimense, Espinal-Colombia. Ibagué: Aquelarre; Universidad del Tolima.

Salgado, Héctor et al. 2008. Estrategias de ocupación prehispánica en la cuenca baja del río Luisa, Guamo-Tolima. Ibagué: Universidad del Tolima.

\section{Salgado, Héctor y Juan Manuel Llanos.} 2010. "El Tolima milenario, un viaje por la diversidad”. En El Tolima milenario, un viaje por la diversidad, editado por Héctor Salgado, 27-137. Ibagué: Universidad del Tolima; Museo del Oro, Banco de la Republica.

Shimada, Izumi. 1987. “Aspectos tecnológicos y productivos de la metalurgia sicán, costa norte del Perú”. En Gaceta Arqueológica Andina 5 (13): 15-21.

\section{Shimada, Izumi, David Goldstein y Urzel} Wagner. 2007. "Sicán Metalworkings Furnaces: Excavation, Archaeometric and Experimental Data and Insights into their Operation and Broader Production Context”. En Lleras 2007a, 337-362.

Simón, Pedro. (1626) 1981. Noticias historiales de las conquistas de Tierra Firme en las Indias Occidentales. Bogotá: Banco Popular.

Thornton, Christopher. 2012. "Archaeometallurgy in the 21st Century”. Reviews in Anthropology 41 (3): 173-187.

Uceda, Santiago. 2010. "Los contextos urbanos de producción artesanal en el complejo arqueológico de las Huacas del Sol y la Luna”. Boletín del Instituto Francés de Estudios Andinos 39 (2): 243-297. 